Syntax Literate: Jurnal Ilmiah Indonesia p-ISSN: 2541-0849

e-ISSN : 2548-1398

Vol. 6, No. 7, Juli 2021

\title{
STUDI EMPIRIS KEPUASAN PELANGGAN E-COMMERCE SECARA GLOBAL
}

\section{Rizky Pratama Ananda, Ahyar Yuniawan}

Universitas Diponegoro (UNDIP) Semarang Jawa Tengah, Indonesia

Email: rizkypratamaananda@gmail.com, ahyar.yuniawan@live.undip.ac.id

\begin{abstract}
Abstrak
Perdagangan Elektronik atau biasa disebut e-commerce adalah media jual beli barang dan jasa melalui sistem online. Kemajuan teknologi dan informasi saat ini menyebabkan bisnis e-commerce saat ini berkembang sangat pesat di seluruh dunia. Namun perbedaan budaya di setiap negara dapat menyebabkan faktor-faktor yang mempengaruhi tingkat kepuasan pelanggan dengan penggunaan sistem e-commerce bervariasi di setiap negara. Berdasarkan hal itu, penelitian ini bertujuan untuk menentukan faktor-faktor yang paling mempengaruhi tingkat kepuasan pelanggan terhadap penggunaan sistem e-commerce secara global. Penelitian ini menggunakan metode meta-analisis yang dilakukan dengan mengumpulkan beberapa hasil studi sebelumnya mengenai kepuasan pelanggan terhadap penggunaan sistem $e$ commerce di berbagai negara. Kesimpulan yang dapat ditarik dari penelitian ini adalah kepercayaan adalah faktor yang paling mempengaruhi kepuasan pelanggan dalam penggunaan sistem e-commerce secara global.
\end{abstract}

Kata Kunci: e-commerce; online; kepuasan pelanggan; percaya

\section{Abstract}

Electronic Commerce or commonly called e-commerce is a media of buying and selling goods and services through an online system. Advances in technology and information at this time cause e-commerce business is currently growing very rapidly throughout the world. However cultural differences in each country can cause factors that affect the level of customer satisfaction with the use of $e$ commerce systems vary in each country. Based on that, this study aims to determine the factors that most influence the level of customer satisfaction with the use of e-commerce systems globally. This research uses a meta-analysis method conducted by gathering some of the results of previous studies regarding customer satisfaction with the use of e-commerce systems in various countries. The conclusion that can be drawn from this research is trust is the factor that most influences customer satisfaction in the use of e-commerce systems globally.

Keywords: e-commerce; online; customer satisfaction; trust

\section{Pendahuluan}

E-commerce mengacu pada transaksi bisnis atau aktivitas manajerial menggunakan internet. E-commerce berkembang sangat pesat dan menyediakan

\begin{tabular}{|c|c|}
\hline How to cite: & $\begin{array}{l}\text { Ananda, Rizky Pratama., Ahyar Yuniawan (2021) Studi Empiris Kepuasan Pelanggan E-Commerce Secara } \\
\text { Global. Syntax } \\
\text { literate.v6i7.3541 }\end{array}$ \\
\hline $\begin{array}{l}\text { E-ISSN: } \\
\text { Published by: }\end{array}$ & $\begin{array}{l}\text { 2548-1398 } \\
\text { Ridwan Institute }\end{array}$ \\
\hline
\end{tabular}


kesempatan besar untuk berbisnis (Sharma \& Lijuan, 2015). E-commerce merupakan elemen penting dalam kehidupan bisnis masa kini. Era digital sekarang menuntut segalanya untuk benar-benar efektif dan efisien (Hendrayati, dkk., 2015). Era digital yang berkembang pesat tersebut juga menghasilkan peluang dan kesempatan untuk meningkatkan skala bisnis 10 hingga 20 kali lipat dibandingkan bisnis tradisional untuk memperluas bisnisnya hingga ke seluruh dunia (Lawrence \& Tar, 2010). Untuk memenangkan persaingan, perusahaan harus mengklasifikasikan diri mereka sebagai perusahaan berbasis digital, inovatif dalam berkreasi menciptakan produk yang menarik, pertimbangkan harga dan tempat, dan menggunakan platform e-commerce berbasis digital (Lawrence \& Tar, 2010).

Dalam sistem e-commerce, kepuasan pelanggan berkontribusi penting pada keberlangsungan bisnis perusahaan yang sangat bergantung pada pelanggannya. Maka dari itu, menjaga dan mempertahankan pelanggan tidak terhindarkan karena pada faktanya konsumen memberikan profit bagi bisnis perusahaan (Khalid, Lee, Choi, \& Ahn, 2018). Kepuasan pelanggan adalah seberapa puas pelanggan dengan produk/ layanan yang disediakan, ini berkaitan dengan kepercayaan personal. Tingkat kepuasan pelanggan yang lebih tinggi akan mengarah pada loyalitas konsumen yang lebih besar (Zins, 2001).

Salah satu langkah untuk meningkatkan bisnis perusahaan yaitu dengan mengembangkan bisnis hingga ke seluruh dunia. Menurut World Population Review (2021), per Juni 2021 jumlah negara yang diakui oleh PBB (Perserikatan BangsaBangsa) berjumlah 197 negara. Jumlah tersebut termasuk 193 negara yang telah menjadi member, 2 negara yang tidak di observasi PBB karena dianggap negara suci (Vatikan dan Palestina), Kosovo yang masih masuk dalam teritorial Serbia, dan Taiwan yang masih masuk dalam teritori Cina. Selain itu jika negara yang terdaftar sebagai member di PBB dibagi berdasarkan benuanya, sebanyak 27\% jumlah negara di dunia berada di benua Afrika dengan 54 negara. Benua Asia-Oseania memiliki jumlah negara sebanyak 61 negara, Eropa memiliki 43 negara, dan benua Amerika memiliki 35 negara (World Population Review, 2021). Berdasarkan hal tersebut, sebuah perusahaan $e$ commerce perlu mengetahui bahwa setiap negara-negara memiliki perbedaan budayanya masing-masing. Perbedaan budaya tersebut dapat mempengaruhi tingkat kepuasaan pelanggan terhadap penggunaan sistem $e$-commerce tersebut.

Tujuan penelitian ini adalah untuk menginvestigasi faktor yang paling mempengaruhi tingkat kepuasan pelanggan dalam menggunakan sistem e-commerce di seluruh dunia. Dari perspektif perusahaan tingkat kepuasan pelanggan memiliki kontribusi besar terhadap keberlangsungan bisnis perusahaan (Khalid et al., 2018). Berdasarkan penelitian-penelitian yang telah ada sebelumnya, pembahasan mengenai kepuasan pelanggan di dalam e-commerce ini hanya terbatas di suatu negara saja dan belum ada yang melakukan penelitian dalam skala global. Oleh karena itu, penelitian ini dapat memberikan gambaran baru mengenai faktor apa yang paling mempengaruhi kepuasan pelanggan e-commerce secara global. 


\section{Metode Penelitian}

Dalam penelitian ini, disajikan faktor-faktor yang mempengaruhi kepuasan pelanggan pada e-commerce dengan mengambil sampel penelitian dari temuan penelitian beberapa peneliti independen dari beberapa negara pada tiap benua di dunia. Dalam penelitian ini digunakan metode meta-analisis yaitu teknik meringkas dan menguji hasil statistik dari temuan peneliti independen dalam jumlah tertentu yang terkait dengan topik yang sama (Curtis, Abratt, Rhoades, \& Dion, 2011). Menurut (Bredzel-Skowera \& Turek, 2015), meta-analisis merupakan suatu bentuk penelitian yang menggunakan beberapa hasil penelitian untuk mengorganisasikan dan menggali informasi sebanyak mungkin dari data yang diperoleh, sehingga mendekati kekomprehensifan.

Langkah pertama dalam penelitian menggunakan metode meta-analisis adalah dengan mengumpulkan data atau informasi dari beberapa penelitian terdahulu untuk menciptakan suatu basis data yang berkaitan dengan topik penelitian yang di investigasi. Langkah kedua dalam meta-analisis adalah mengkonversi data-data statistik yang telah dikumpulkan dalam satu skala pengukuran yang sama. Langkah terakhir dalam metaanalisis adalah melakukan prosedur meta-analisis dan menganalisis hasil yang diperoleh. Menurut (Johnson, D. W., \& Johnson, 2002), secara garis besar tujuan utama dari meta-analisis adalah untuk mengatasi tiga masalah umum yaitu kecenderungan sentral, variabilitas, dan prediksi.

Untuk menjamin kualitas data, hanya penelitian yang lengkap yang dimasukan dalam analisis faktor yang mempengaruhi kepuasaan pelanggan pada e-commerce (Ahn \& Kang, 2018). Basis data yang digunakan pada penelitian ini dipilih karena jangkauan dan perluasan penelitian. Hal tersebut memungkinkan penyajian semua faktor yang mempengaruhi kepuasan pelanggan pada e-commerce dari beberapa negara pada tiap benua di dunia.

\section{Hasil dan Pembahasan}

\section{A. Pembentukan Basis Data}

Pembentukan basis data dalam penelitian ini dilakukan dengan mengumpulkan data-data dari beberapa penelitian terdahulu terkait kepuasan pelanggan dalam sistem e-commerce. Pengumpulan data di dapatkan dari artikel dan jurnal-jurnal yang terpercaya dan cukup banyak dijadikan sebagai rujukan oleh penelitian lain. Pengumpulan data tersebut dilakukan dengan teknik purposive sampling yang bersumber dari 20 studi peneliti independen yang telah terpublikasi dan terbagi secara merata masing-masing berjumlah 5 dari tiap benua (Afrika, Eropa, Amerika, dan Asia-Oseania). Berikut adalah karakteristik basis data yang berhasil dikumpulkan dan digunakan dalam penelitian ini: 


\section{Tabel 1}

\section{Karakteristik Basis Data}

\begin{tabular}{lcl}
\hline Benua & $\begin{array}{c}\text { Jumlah } \\
\text { Artikel }\end{array}$ & Negara \\
\hline Afrika & 5 & Afrika Selatan, Nigeria, Mesir \\
Eropa & 5 & Serbia, Yunani, Portugal, Britania Raya, \\
Amerika & 5 & Brazil, US, Mexico \\
Asia-Oseania & 5 & Malaysia, Thailand, India, Indonesia, Iran \\
\hline
\end{tabular}

\section{B. Konversi Data}

Dari basis data yang telah dibuat tersebut, selanjutnya dilakukan konversi data dengan menggunakan skala pengukuran yang sama. Konversi data ini dilakukan dengan mengkonversi faktor-faktor yang mempengaruhi kepuasan pelanggan $e$ commerce dari artikel-artikel yang ada dengan menggunakan skala pengukuran yang sama yaitu menggunakan nilai signifikansi faktor-faktor tersebut terhadap kepuasan pelanggan e-commerce. Secara singkat, faktor-faktor yang tidak berpengaruh terhadap kepuasan pelanggan e-commerce tidak digunakan dalam meta-analisis. Hasil dari konversi data dalam meta-analisis tersebut dapat dilihat dalam tabel berikut.

Tabel 2

Hasil Konversi Data

Afrika

\begin{tabular}{|c|c|c|c|c|c|}
\hline Negara & Nigeria & Nigeria & $\begin{array}{c}\text { Afrika } \\
\text { Selatan }\end{array}$ & $\begin{array}{l}\text { Afrika } \\
\text { Selatan }\end{array}$ & Mesir \\
\hline Variabel / Penulis & $\begin{array}{l}\text { (Nwokah } \\
\& \\
\text { Gladson- } \\
\text { Nwokah, } \\
2016 \text { ) }\end{array}$ & $\begin{array}{l}\text { (EC Iluno, } \\
\text { YJ Asmau, } \\
\text { LO } \\
\text { Mustapha, } \\
\text { 2019) }\end{array}$ & $\begin{array}{l}\text { (Chinomona, } \\
\text { Masinge, \& } \\
\text { Sandada, } \\
\text { 2014) }\end{array}$ & $\begin{array}{l}\text { (Rudansky- } \\
\text { Kloppers, } \\
\text { 2014) }\end{array}$ & $\begin{array}{l}\text { (Elsaadany \& } \\
\text { Kadry, 2014) }\end{array}$ \\
\hline Service Quality & 1 & & & & \\
\hline Perceived Value & & & 1 & & \\
\hline $\begin{array}{l}\text { Internet Reliability / } \\
\text { Reliability }\end{array}$ & & 1 & & & \\
\hline $\begin{array}{l}\text { Internet Efficiency } \\
\text { /Efficiency }\end{array}$ & & 1 & & & \\
\hline Security & & 1 & & 1 & \\
\hline Logistics & & & & 1 & \\
\hline Convenience & & & & 1 & \\
\hline Price Experience & & & & 1 & \\
\hline Product Variety & & & & 1 & \\
\hline Respectively & & & & 1 & \\
\hline Perceived Risk & 1 & & & & \\
\hline Repeat Purchase & 1 & & & & \\
\hline $\begin{array}{l}\text { Repeat } \quad \text { Purchase } \\
\text { Policy }\end{array}$ & 1 & & & & \\
\hline $\begin{array}{l}\text { The Usage Of } \\
\text { Mobile Commerce }\end{array}$ & & & & & 1 \\
\hline
\end{tabular}


Tabel 3

Asia-Oseania

\begin{tabular}{|c|c|c|c|c|c|}
\hline Negara & Malaysia & Thailand & Indonesia & India & Iran \\
\hline $\begin{array}{l}\text { Variabel/ } \\
\text { Penulis }\end{array}$ & $\begin{array}{l}\text { (San } \\
\text { Lim, } \\
\text { Heng, } \\
\text { Ng, \& } \\
\text { Cheah, } \\
\text { 2016) }\end{array}$ & $\begin{array}{l}\text { (Chen, Yen, } \\
\text { Pornpriphet, } \\
\& \text { Widjaja, } \\
\text { 2015) }\end{array}$ & $\begin{array}{l}\text { Alif, } \\
\text { Pangaribuan, \& } \\
\text { Wulandari, } \\
\text { 2017) }\end{array}$ & $\begin{array}{l}\text { (Natarajan, } \\
\text { Balasubramanian, } \\
\& \quad \text { Kasilingam, } \\
\text { 2017) }\end{array}$ & $\begin{array}{l}\text { (Ghalandari, } \\
\text { 2012) }\end{array}$ \\
\hline $\begin{array}{l}\text { Expectation } \\
\text { Confirmation }\end{array}$ & & & 1 & & \\
\hline $\begin{array}{l}\text { Perceived } \\
\text { Usefulness }\end{array}$ & & & & 1 & \\
\hline $\begin{array}{l}\text { Service } \\
\text { Quality }\end{array}$ & 1 & 1 & & & 1 \\
\hline $\begin{array}{ll}\text { Trust / E- } \\
\text { Trust }\end{array}$ & & 1 & & & 1 \\
\hline Web Design & & & 1 & & \\
\hline $\begin{array}{l}\text { Price / } \\
\text { Transaction } \\
\text { Cost }\end{array}$ & 1 & & & & \\
\hline $\begin{array}{l}\text { Website } \\
\text { Features }\end{array}$ & & & 1 & & \\
\hline Mobility & & & & & \\
\hline $\begin{array}{l}\text { Perceived } \\
\text { Enjoyment }\end{array}$ & & & & 1 & \\
\hline $\begin{array}{l}\text { Usability / } \\
\text { Usefullness }\end{array}$ & 1 & & & & \\
\hline Credibility & 1 & & & & \\
\hline $\begin{array}{l}\text { Information } \\
\text { Quality }\end{array}$ & & 1 & & & \\
\hline $\begin{array}{l}\text { System } \\
\text { Quality }\end{array}$ & & 1 & & & \\
\hline Time Saving & & & 1 & & \\
\hline $\begin{array}{l}\text { Less } \\
\text { Expensive / } \\
\text { Cost Savings }\end{array}$ & & & 1 & & \\
\hline $\begin{array}{l}\text { Perceived } \\
\text { Ease Of Use }\end{array}$ & & & 1 & 1 & \\
\hline $\begin{array}{l}\text { Service } \\
\text { Security }\end{array}$ & & & 1 & & \\
\hline $\begin{array}{l}\text { Social } \\
\text { Influence }\end{array}$ & & & 1 & & \\
\hline $\begin{array}{l}\text { Perceived } \\
\text { Risk }\end{array}$ & & & & 1 & \\
\hline $\begin{array}{l}\text { Personal } \\
\text { Innovativenes } \\
s\end{array}$ & & & & 1 & \\
\hline $\begin{array}{l}\text { Perceived } \\
\text { Commitment }\end{array}$ & & & & & 1 \\
\hline
\end{tabular}


Rizky Pratama Ananda, Ahyar Yuniawan

To Csr

Tabel 4

Eropa

\section{Hasil Konversi Data}

\begin{tabular}{|c|c|c|c|c|c|}
\hline Negara & Britania & Serbia & Portugal & Yunani & Serbia \\
\hline Variabel / Penulis & $\begin{array}{l}\text { (Valvi \& } \\
\text { West, } \\
\text { 2013) }\end{array}$ & $\begin{array}{l}\text { (Marinkovic } \\
\& \quad \text { Kalinic, } \\
\text { 2017) }\end{array}$ & $\begin{array}{l}\text { (Loureiro, } \\
\text { Cavallero, } \\
\& \\
\text { Miranda, } \\
\text { 2018) }\end{array}$ & $\begin{array}{l}\text { (Pappas, Pateli, } \\
\text { Giannakos, \& } \\
\text { Chrissikopoulos, } \\
\text { 2014) }\end{array}$ & $\begin{array}{l}\text { (Vasic, } \\
\text { Kilibarda, } \\
\text { \& Kaurin, } \\
\text { 2019) }\end{array}$ \\
\hline Perceived Usefulness & & 1 & & & \\
\hline Trust / E-Trust & 1 & & & 1 & \\
\hline Perceived Value & 1 & & & & \\
\hline Security & & & & & 1 \\
\hline Convenience & 1 & & & & \\
\hline Web Design & 1 & & & & \\
\hline $\begin{array}{l}\text { Psychological Factors } \\
\text { (Personality) }\end{array}$ & 1 & & & & \\
\hline Inertia & 1 & & & & \\
\hline $\begin{array}{l}\text { Computer Knowledge - } \\
\text { Experience }\end{array}$ & 1 & & 1 & & \\
\hline $\begin{array}{l}\text { Price / Transaction } \\
\text { Cost }\end{array}$ & 1 & & & & 1 \\
\hline Website Features & 1 & & & & \\
\hline Mobility & & 1 & & & \\
\hline Perceived Enjoyment & & 1 & & & \\
\hline Customization & & 1 & & & \\
\hline Time Saving & & & & & 1 \\
\hline Information Availibility & & & & & 1 \\
\hline Social Influence & & & 1 & & \\
\hline $\begin{array}{l}\text { Perceived Fashion } \\
\text { Website Quality }\end{array}$ & & & 1 & & \\
\hline $\begin{array}{l}\text { Performance } \\
\text { Expectancy }\end{array}$ & & & 1 & & \\
\hline Technology Quality & & & 1 & & \\
\hline Post Experience & & & 1 & & \\
\hline Effort Expectancy & & & & 1 & \\
\hline Experienced Customers & & & & 1 & \\
\hline Self-Efficacy & & & & 1 & \\
\hline Shipping & & & & & 1 \\
\hline Product Quality & & & & & 1 \\
\hline
\end{tabular}




\section{Tabel 5}

Amerika

\section{Hasil Konversi Data}

\begin{tabular}{|c|c|c|c|c|c|}
\hline Negara & Amerika & Amerika & Brazil & Brazil & Meksiko \\
\hline Variabel / Penulis & $\begin{array}{l}(\mathrm{Wu}, \\
2013)\end{array}$ & $\begin{array}{l}\text { (Nisar \& } \\
\text { Prabhakar, } \\
\text { 2017) }\end{array}$ & $\begin{array}{l}\text { (Ceribeli, } \\
\text { da Silva } \\
\text { Tamashiro, } \\
\text { \& Merlo, } \\
2017 \text { ) }\end{array}$ & $\begin{array}{l}\text { (Tontini, da } \\
\text { Silva, Beduschi, } \\
\text { Zanin, \& } \\
\text { Marcon, 2015) }\end{array}$ & $\begin{array}{l}\text { (Peña- } \\
\text { García, } \\
\text { Gil-Saura, } \\
\& \\
\text { Rodríguez } \\
\text {-Orejuela, } \\
\text { 2018) }\end{array}$ \\
\hline Distributive Justice & 1 & & & & \\
\hline Interactional Justice & 1 & & & & \\
\hline Expectation Confirmation & 1 & & & & \\
\hline Perceived Usefulness & 1 & & & & \\
\hline Trust / E-Trust & 1 & & & & \\
\hline Perceived Value & & 1 & & & 1 \\
\hline Customer Expectations & & 1 & & & \\
\hline Perceived Quality & & 1 & & & \\
\hline Loyalty & & 1 & & & \\
\hline Convenience & & & 1 & & \\
\hline Product Variety & & & 1 & & \\
\hline $\begin{array}{l}\text { The Communication Of } \\
\text { Online Retailing }\end{array}$ & & & & 1 & \\
\hline Helpful /Fault Recovery & & & & 1 & \\
\hline Content Reliability & & & 1 & & \\
\hline Repeat Purchase Policy & & & 1 & & \\
\hline Shipping & & & 1 & & \\
\hline Online Flow State & & & 1 & & \\
\hline Site Accessibility/Speed & & & & 1 & \\
\hline Buying Reliability & & & & 1 & \\
\hline $\begin{array}{l}\text { Flexibility Of Website } \\
\text { Design/Services }\end{array}$ & & & & 1 & \\
\hline
\end{tabular}

\section{Hasil Analisis}

Berdasarkan hasil konversi data, selanjutnya dilakukan analisis data untuk mengetahui faktor yang paling mempengaruhi kepuasan pelanggan menggunakan sistem e-commerce secara global. Dari beberapa faktor yang mempengaruhi kepuasan pelanggan menggunakan sistem e-commerce secara global, selanjutnya faktor-faktor tersebut diakumulasikan dan di analisis jumlahnya dari total 20 artikel yang telah dikumpulkan. Semakin banyak jumlah suatu faktor menjadi salah satu variabel penelitian, maka semakin besar pula pengaruh faktor tersebut terhadap kepuasan pelanggan e-commerce secara global. 


\section{Tabel 6}

Hasil Analisis Data

\begin{tabular}{lccc}
\hline \multicolumn{1}{c}{ Faktor/Variabel } & Jumlah & $\begin{array}{c}\text { Total } \\
\text { Faktor/Variabel }\end{array}$ & $\begin{array}{c}\text { Persentase } \\
(\mathbf{\%})\end{array}$ \\
\hline Trust & 5 & 61 & 8.20 \\
Perceived Value & 4 & 61 & 6.56 \\
Service Quality & 4 & 61 & 6.56 \\
Perceived Usefulness & 3 & 61 & 4.92 \\
Security & 3 & 61 & 4.92 \\
Convenience & 3 & 61 & 4.92 \\
Web Design & 3 & 61 & 4.92 \\
Price/Transaction Cost & 3 & 61 & 4.92 \\
\hline
\end{tabular}

Berdasarkan hasil konversi data meta analisis, diketahui bahwa faktor yang paling mempengaruhi kepuasan pelanggan e-commerce secara global adalah faktor trust/kepercayaan. Kepercayaan pada dasarnya dilihat sebagai mekanisme umum untuk pengurangan kompleksitas sosial dan risiko yang dirasakan dari transaksi (Wu, 2013). Selain itu trust juga berfungsi sebagai alat ukur yang valid untuk menilai tingkat kepercayaan pada keandalan dan integritas antar sesama mitra bisnis (Valvi \& West, 2013).

Dari total 61 faktor yang ditemukan dari konversi data, jumlah penggunaan faktor trust ini sebagai variabel penelitian yaitu 5 sedangkan faktor lainnya seperti perceived value, service quality, dan beberapa faktor lainnya dibawah faktor trust tersebut. Hasil analisis data dari beberapa faktor teratas dalam penggunaan sistem $e$ commerce tersebut dapat dilihat pada tabel 6 .

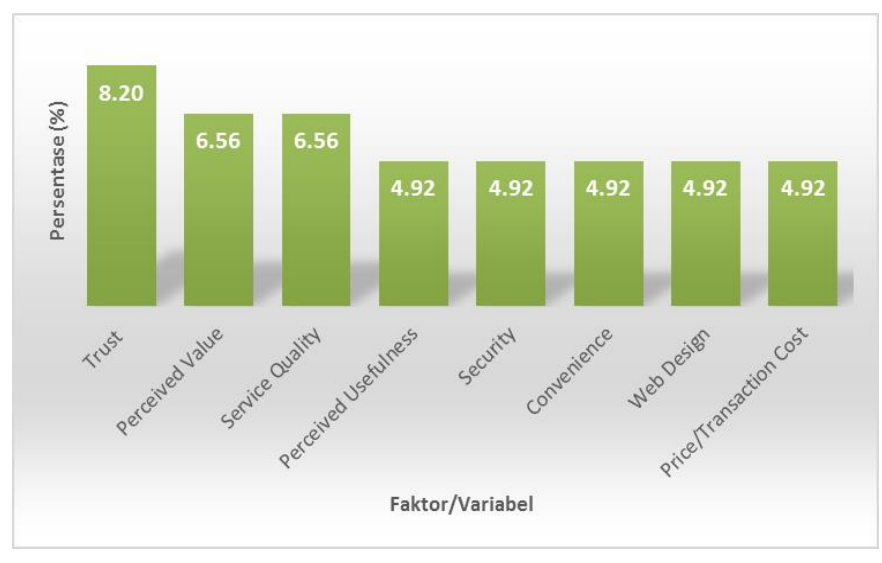

Grafik 1

\section{Persentase Faktor Paling Mempengaruhi Kepuasan Pelanggan E-commerce}

Jika dilihat berdasarkan persentasenya, faktor trust memiliki persentase sebesar 8.20\% dari keseluruhan faktor yang mempengaruhi kepuasan pelanggan e-commerce secara global dalam meta-analisis ini. Persentase beberapa faktor lain dibawah trust yang paling mempengaruhi kepuasan pelanggan e-commerce secara global dalam metaanalisis ini seperti perceived value, service quality, dan lain-lain dapat dilihat pada grafik 1. Menurut (Marinkovic \& Kalinic, 2017) beberapa studi telah menemukan 
bahwa kepercayaan dan kepuasan pelanggan berhubungan sangat kuat. Saat konsumen mempercayai sebuah perusahaan penyedia e-commerce, mereka akan menjadi lebih loyal bahkan merekomendasikannya kepada orang lain dalam bentuk word-of-mouth. Oleh karena itu, berdasarkan hasil penelitian di atas para pelaku bisnis di bidang $e$ commerce wajib untuk menjaga kepercayaan dari para pelanggannya. Kepercayaan ini menjadi sangat penting karena hal paling utama dari bisnis secara daring ini adalah kepercayaan pelanggan dari nilai produk atau jasa yang di tawarkan dimana nilai produk atau jasa tersebut baru bisa dirasakan ketika pelanggan baru benar-benar menggunakannya, tidak seperti transaksi offline dimana para pelanggan bisa melihat dan mencoba produk atau jasa yang diinginkan. Dengan menjaga kepercayaan pelanggan tersebut tentunya para pelaku bisnis di bidang e-commerce dapat mencapai kepuasan pelanggannya sehingga pelanggan tersebut juga akan selalu loyal dengan perusahaan $e$ commerce tersebut. Selain itu menurut (Wu, 2013), kepercayaan mendorong konsumen untuk selalu berhubungan dengan toko akibat dari nilai yang telah mereka rasakan dalam bertransaksi menggunakan sistem $e$-commerce tersebut.

\section{Kesimpulan}

Signifikansi utama dari penelitian ini adalah untuk mengetahui faktor paling utama yang mempengaruhi tingkat kepuasan konsumen dalam menggunakan sistem $e$ commerce. Berdasarkan hasil analisis yang telah dilakukan, hasil tersebut mengindikasikan bahwa faktor yang paling mempengaruhi tingkat kepuasan pelanggan dalam menggunakan sistem e-commerce adalah trust atau kepercayaan. 


\section{BIBLIOGRAFI}

Ahn, EunJin, \& Kang, Huyn. (2018). Introduction to Systematic Review and MetaAnalysis: A Health Care Perspective. Korean Journal of Anesthesiology, 71(2), 138. Google Scholar

Alif, Muhammad Gunawan, Pangaribuan, Christian Haposan, \& Wulandari, Novi Retno. (n.d.). The Factors Affecting Customer Satisfaction, Loyalty, and Word of Mouth Towards Online Shopping for Millennial Generation in Jakarta. (2017), 130. Google Scholar

Bredzel-Skowera, Katarzyna, \& Turek, Tomasz. (2015). The Prospects of E-commerce in Poland. Procedia Computer Science, 65(Iccmit), 1114-1123. https://doi.org/10.1016/j.procs.2015.09.038 Google Scholar

Ceribeli, Harrison Bachion, da Silva Tamashiro, Helenita Rodrigues, \& Merlo, Edgard Monforte. (2017). Online flow and e-satisfaction in high involvement purchasing processes. BASE-Revista de Administração e Contabilidade Da Unisinos (ISSN: 1984-8196), 14(1), 16-29. Google Scholar

Chen, Jengchung Victor, Yen, David C., Pornpriphet, Wannasri, \& Widjaja, Andree E. (2015). E-commerce web site loyalty: A cross cultural comparison. Information Systems Frontiers, 17(6), 1283-1299. Google Scholar

Chinomona, Richard, Masinge, Godrey, \& Sandada, Maxwell. (2014). The influence of e-service quality on customer perceived value, customer satisfaction and loyalty in South Africa. Mediterranean Journal of Social Sciences, 5(9), 331. Google Scholar

Curtis, Tamilla, Abratt, Russell, Rhoades, Dawna, \& Dion, Paul. (2011). Customer Loyalty, Repurchase and Satisfaction: A Meta-Analytical Review. Journal of Consumer Satisfaction, Dissatisfaction \& Complaining Behavior, 24, 1-26. Google Scholar

EC Iluno, YJ Asmau, LO Mustapha, NM Ahmed. (2019). Esut journal of management sciences volume 12, numbers 1 \& 2, 2019. 12(2013), 97-105. Google Scholar

Elsaadany, Olla, \& Kadry, Mona. (2014). Evaluation of the Factors That Affect the Mobile Commerce in Egypt and Its Impact on Customer Satisfaction. In Advanced Approaches to Intelligent Information and Database Systems (pp. 213-224). Springer. Google Scholar

Ghalandari, Kamal. (2012). The Effect of E-Service Quality on E-Trust and ESatisfaction as Key Factors Influencing Creation of E-Loyalty in E-Business Context: The Moderating Role of Situational Factors. 2(12), 12847-12855. Google Scholar

Johnson, D. W., \& Johnson, R. T. (2002). Cooperative learning methods: a metaanalysis. Journal of Research in Education, 12(1), 5-24. 
Khalid, Alotaibi, Lee, Ook, Choi, Minkyong, \& Ahn, Jongchang. (2018). The effects of customer satisfaction with e-commerce system. Journal of Theoretical and Applied Information Technology, 96(2), 481-491. Google Scholar

Lawrence, Japhet E., \& Tar, Usman A. (2010). Barriers to ecommerce in developing countries. Journal of Global Information Management, 19(3), 30-44. https://doi.org/10.4018/jgim.2011070102

Loureiro, Sandra M. C., Cavallero, Luisa, \& Miranda, Francisco Javier. (2018). Fashion brands on retail websites: Customer performance expectancy and e-word-ofmouth. Journal of Retailing and Consumer Services, 41(December 2017), 131141. https://doi.org/10.1016/j.jretconser.2017.12.005 Google Scholar

Marinkovic, Veljko, \& Kalinic, Zoran. (2017). Antecedents of customer satisfaction in mobile commerce: Exploring the moderating effect of customization. Online Information Review, 41(2), 138-154. https://doi.org/10.1108/OIR-11-2015-0364 Google Scholar

Natarajan, Thamaraiselvan, Balasubramanian, Senthil Arasu, \& Kasilingam, Dharun Lingam. (2017). Understanding the intention to use mobile shopping applications and its in $\mathrm{fl}$ uence on price sensitivity. Journal of Retailing and Consumer Services, 37(January), 8-22. https://doi.org/10.1016/j.jretconser.2017.02.010 Google Scholar

Nisar, Tahir M., \& Prabhakar, Guru. (2017). What factors determine e-satisfaction and consumer spending in e-commerce retailing? Journal of Retailing and Consumer Services, 39, 135-144. Google Scholar

Nwokah, N. Gladson, \& Gladson-Nwokah, Juliet. (2016). Online shopping experience and customer satisfaction in Nigeria. Journal of Economics and Sustainable Development, 7(22), 176-185. Google Scholar

Pappas, Ilias O., Pateli, Adamantia G., Giannakos, Michail N., \& Chrissikopoulos, Vassilios. (2014). Moderating effects of online shopping experience on customer satisfaction and repurchase intentions. https://doi.org/10.1108/IJRDM-03-20120034 Google Scholar

Peña-García, Nathalie, Gil-Saura, Irene, \& Rodríguez-Orejuela, Augusto. (2018). Eloyalty formation: A cross-cultural comparison of Spain and Colombia. Journal of Electronic Commerce Research, 19(4), 336-356. Google Scholar

Rudansky-Kloppers, Sharon. (2014). Investigating factors influencing customer online buying satisfaction in Gauteng, South Africa. International Business \& Economics Research Journal (IBER), 13(5), 1187-1198. Google Scholar

San Lim, Ying, Heng, Pui Chuan, Ng, Tuan Hock, \& Cheah, Chew Sze. (2016). Customers' online website satisfaction in online apparel purchase: A study of 
Generation Y in Malaysia. Asia Pacific Management Review, 21(2), 74-78. Google Scholar

Sharma, Gajendra, \& Lijuan, Wang. (2015). The effects of online service quality of ecommerce websites on user satisfaction. Collection Management, 33(3), 133-141. https://doi.org/10.1300/J105v09n02_12

Tontini, Gerson, da Silva, Júlio Cesar, Beduschi, Eliane Fátima Strapazzon, Zanin, Elis Regina Mulinari, \& Marcon, Margarete de Fátima. (2015). Nonlinear impact of online retail characteristics on customer satisfaction and loyalty. International Journal of Quality and Service Sciences, 7(2-3), 152-169. https://doi.org/10.1108/IJQSS-02-2015-0021 Google Scholar

Valvi, Aikaterini C., \& West, Douglas C. (2013). E-loyalty is not all about trust, price also matters: Extending expectation-confirmation theory in bookselling websites. Journal of Electronic Commerce Research, 14(1), 99-123. Google Scholar

Vasic, Nebojsa, Kilibarda, Milorad, \& Kaurin, Tanja. (2019). The Influence of Online Shopping Determinants on Customer Satisfaction in the Serbian Market. Journal of Theoretical and Applied Electronic Commerce Research, 14(2), 0-0. https://doi.org/10.4067/s0718-18762019000200107 Google Scholar

$\mathrm{Wu}$, Ing Long. (2013). The antecedents of customer satisfaction and its link to complaint intentions in online shopping: An integration of justice, technology, and trust. International Journal of Information Management, 33(1), 166-176. https://doi.org/10.1016/j.ijinfomgt.2012.09.001 Google Scholar

Zins, Andreas H. (2001). Relative attitudes and commitment in customer loyalty models. International Journal of Service Industry Management, 12(3), 269-294. https://doi.org/10.1108/eum0000000005521 Google Scholar

\section{Copyright holder:}

Rizky Pratama Ananda, Ahyar Yuniawan (2021)

First publication right:

Syntax Literate: Jurnal Ilmiah Indonesia

This article is licensed under:

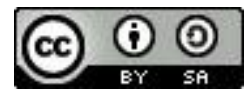

